\title{
Social factors associated with increases in tuberculosis notifications
}

\author{
K. Tocque*, M. Regan**, T. Remmington*, N.J. Beeching ${ }^{+}$, I. Jamieson*, Q. Syed*, P.D.O. Davies*
}

Social factors associated with increases in tuberculosis notifications. K. Tocque, M. Regan, T. Remmington, N.J. Beeching, I. Jamieson, Q. Syed, P.D.O. Davies. C)ERS Journals Ltd 1999.

ABSTRACT: This study assessed the contribution of immigration and deprivation to the changes in tuberculosis notifications in Liverpool over the last 20 yrs.

Ethnic origin was retrospectively assigned to all named cases from 1974 to 1995. Average tuberculosis rates were calculated for the 33 council wards in Liverpool for 1981-1985 and 1991-1995. Multiple regression was used to determine the independent effects of socioeconomic and population measures from the 1981 and 1991 censuses in explaining these ward-based rates.

Since 1974, there has been a steady increase in the percentage of non-Caucasian cases of tuberculosis, from $8.7 \%$ in $1975-1977,15.1 \%$ in $1981-1983,17.5 \%$ in 1987 1989 to $28.0 \%$ in $1993-1995$. Multiple regression analysis showed that in 1981 only unemployment had a significant independent relationship with tuberculosis rates, but in 1991 two indices of deprivation and ethnicity had a significant influence.

The increasing proportion of non-Caucasian tuberculosis cases, both while the number of notifications was declining before 1987 and increasing afterwards, is not necessarily consistent with the concept that immigration has influenced the recent increase. However, the fact that ethnicity now independently explains some of the council ward variations but did not in the early 1980s suggests that immigration does influence the distribution of disease within the city.

Eur Respir J 1999; 13: 541-545.
*CDSC North West, Public Health Laboratory, Fazakerley Hospital, Liverpool, UK. **Liverpool Health Authority, Hamilton House, Liverpool, UK. ${ }^{+}$School of Tropical Medicine, University of Liverpool, Liverpool, UK. "Tuberculosis Research Unit, Cardiothoracic Centre, Liverpool, UK.

Correspondence: K. Tocque

CDSC North West

Public Health Laboratory Service

Fazakerley Hospital

Lower Lane

Liverpool L9 7AL

UK

Fax: 441515240362

Keywords: Deprivation

immigration

tuberculosis

Received: May 181998

Accepted after revision October 191998

This project was financially supported by the Smith Charity.
Since the mid-1980s, tuberculosis notifications have increased in both developing and developed countries, including the UK [1]. The factors underlying the observed increase in these countries remain unclear but human immunodeficiency virus, increasing socioeconomic deprivation and migration from developing to developed countries are known to play a part in this increase [2]. In England and Wales, tuberculosis has been increasing since 1987 and remains strongly associated with poverty [3-5]. However, the ethnic composition of a population is also known to affect the prevalence of tuberculosis [5].

Several recent studies have found that socioeconomic factors, such as overcrowding and unemployment, are associated with tuberculosis rates in England and Wales [6, 7], while other reports from Western Europe [5, 8], New Zealand [9] and Canada [10] have documented that immigration from nations where tuberculosis is common has been largely responsible for slowing the decrease in morbidity rates in these developed countries. These studies have shown that the incidence of tuberculosis in immigrant communities is far greater than in the indigenous population. Therefore, it is necessary to assess the relative importance of various factors, which may be interrelated, in order to understand the current epidemiology of the disease.
Although other cities in the UK have exhibited a higher annual incidence of tuberculosis in the last $10 \mathrm{yrs}$, Liverpool has experienced one of the largest relative increases in tuberculosis notifications from 35 in 1987, when the national increase began, to 80 in 1993 [1]. Thus, this has been used as a working model to try to dissect out the independent effects of immigration and social deprivation. The period of this study (1974-1995) covers the years around the two most recent national censuses, carried out in 1981 and 1991, in which ethnic origin was available from census data. It is hoped that the result of this study may provide helpful information to guide social and economic policy at a local level in the battle to eliminate tuberculosis.

\section{Methods}

Data was obtained from the database of notifications in Liverpool city for the years 1974-1995, held by the Consultant in Communicable Disease Control (CCDC). Surnames were used to assign an ethnic code to each individual based on the Office of National Statistics Directory of Ethnic Names [11]. This directory largely concentrates on African and religious (Hindu/Muslim/ Sikh) names, and Caucasian and South-East Asian names 
were assigned by conjecture. Caribbean names were indistinguishable from assigned "Caucasian" names and were therefore disregarded. This was not considered to be a significant bias as the higher incidence populations for tuberculosis are South-East Asian and Black African. Both surnames and given first names were used to determine ethnicity, although where these contradicted, the ethnic code derived from the surname was used. Those names which defied classification in the above way were assigned "unknown" [12].

The residential area of all cases was classified by council ward to enable a socioeconomic analysis of tuberculosis rates in Liverpool. Addresses were available for the vast majority of subjects. For individuals whose ward was unassigned on the CCDC database, addresses were located using a street atlas and wards allocated from a Liverpool City Council map.

Underprivileged area scores (and their components) were obtained from B. Jarman for each council ward in Liverpool from the 1981 and 1991 National censuses. Council ward population estimates were obtained from the Liverpool Health Authority and used to calculate average annual rates of tuberculosis in 1981-1985 and 1991-1995. Multivariate regression models (stepwise) were then applied to these socioeconomic and population measures to assess the independent effects of ward-based measures in explaining tuberculosis rates. The Jarman index was chosen because in a previous study this index was found to be the strongest correlate of the notification rate of tuberculosis [4].

\section{Results}

The total number of tuberculosis notifications during the study period was 1,819 . The numbers per year fell steadily from 159 in 1974 to 35 in 1987 (fig. 1). After this, the number rose to a peak of 80 cases in 1993 and declined to 46 and 53 cases in 1994 and 1995, respectively. The proportion of non-Caucasian cases, however, rose throughout the period of study from $8.7 \%$ in $1975-1977,15.1 \%$ in $1981-1983,17.5 \%$ in $1987-1989$ to $28.0 \%$ in $1993-$ 1995.

The overall annual rate of tuberculosis per 100,000 was 16.5 in 1981-1985, falling to 10.8 in 1986-1990 and rising to 12.2 in 1991-1995. The rates by ethnic origin were not determined because population data by ethnicity were unavailable for that time.

The numbers of cases of tuberculosis varied considerably between the council wards of the city, with over a 10fold variation between the highest and lowest rates. All wards had at least one case of tuberculosis, even in the most recent period studied. Over the whole time period, $25 \%$ of cases occurred within the five wards (equivalent to $15 \%$ of the population) with the highest rates of tuberculosis (over 20 cases per 100,000 population). By contrast, $25 \%$ of cases occurred within the 12 wards $(36 \%$ of the population) with the lowest rates of tuberculosis $(<9$ cases per 100,000 population). Two wards, traditionally the home of immigrants to the UK (up to $9 \%$ of the population), showed consistently high rates throughout the period (approximately 25 and 35 per 100,000, respectively). Wards with the lowest levels of immigration $(<0.5 \%$ of the population), but with traditionally high deprivation indices, typically showed a decline in rate from 1981-1985 to 1991. A total of 10 wards showed an increase in rate from 1981-1985 to 1991-1995. No clear patterns emerged to suggest why this occurred, but all these wards had approximately or lower than average rates in 1981-1985 $(\leq 16$ per 100,000$)$.

The median age of Caucasian tuberculosis cases rose significantly over the 20 -yr period, from $54 \mathrm{yrs}$ in the $1970 \mathrm{~s}$ to $60 \mathrm{yrs}$ in the $1990 \mathrm{~s}$ for males $(\mathrm{z}=2.4, \mathrm{p}<0.02)$ and from 49 to 59 for females $(\mathrm{z}=2.6, \mathrm{p}<0.01)$. However, the age of non-Caucasian male (median 43 yrs) and female tuberculosis cases (median 31 yrs) showed no significant change throughout the entire period (fig. 2). Overall, nonCaucasian male and female tuberculosis cases were significantly younger than Caucasian male $(\mathrm{z}=4.87, \mathrm{p}<$ $0.001)$ and female cases $(\mathrm{z}=4.47, \mathrm{p}<0.001)$.

Multivariate analysis of Jarman index variables (tables 1 and 2) for each council ward showed that, in 1981, only unemployment was significantly associated with differences in tuberculosis rates $\left(r^{2}=0.58\right)$. However, in 1991 , three variables had significant independent effects on council ward tuberculosis rates. These were two measures of deprivation: overcrowding $\left(\mathrm{r}^{2}=0.37\right)$ and elderly living alone $\left(r^{2}=0.51\right)$, and one population measure of ethnicity (the proportion of households headed by a person born in the new Commonwealth) $\left(\mathrm{r}^{2}=0.22\right)$. No other variables were significantly associated with council ward variations in tuberculosis rates in either of the two time periods (table 1).

\section{Discussion}

In this study, the incidence of tuberculosis at the 1981 and 1991 population censuses showed different associations with several population and socioeconomic measures in the city of Liverpool. The notification rates in 19811985 were associated independently with unemployment, whereas by 1991-1995, ethnicity, overcrowding and elderly living alone were shown to influence tuberculosis rates.

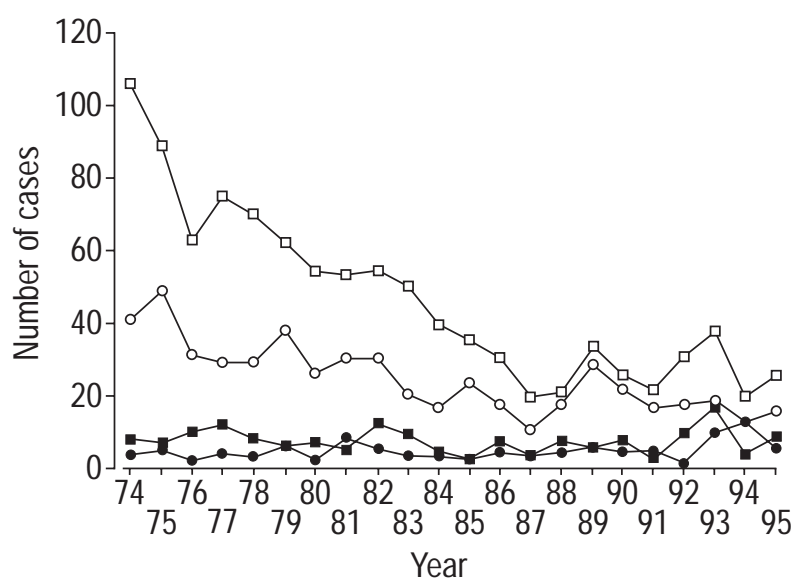

Fig. 1. - Trend in the number of notifications in the city of Liverpool between 1974 and 1995 for Caucasian and non-Caucasian males and females. $-\square-$ : Male (Caucasian); - - - : male (non-Caucasian); ——— : female (Caucasian); ——— : female (non-Caucasian). 

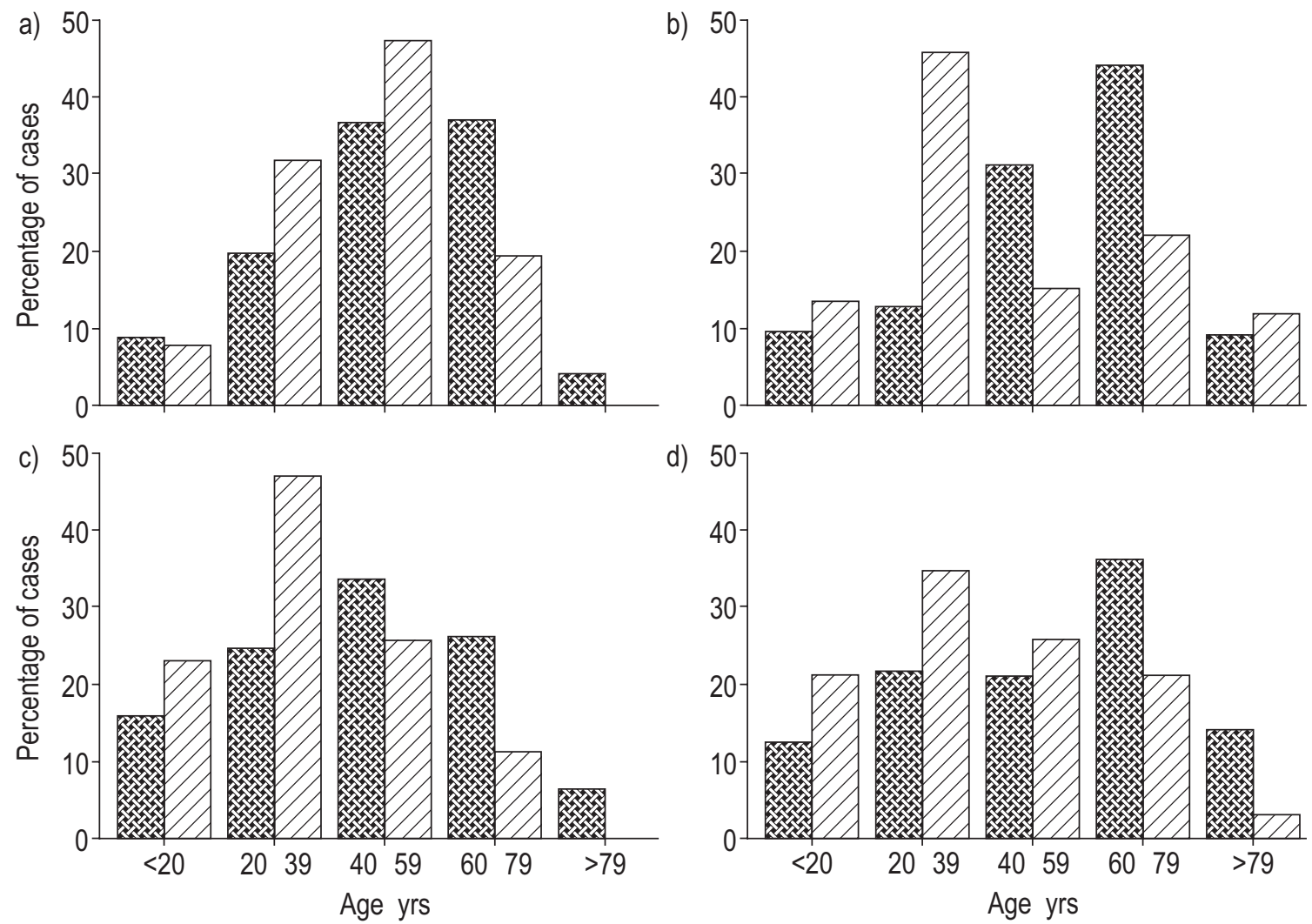

Fig. 2. - Age distributions of Caucasian ( (ख) and non-Caucasian (ש) cases for males in a) 1975-1981 and b) 1989-1995 and females in c) 1975-1981 and d) $1989-1995$

The proportion of non-Caucasian tuberculosis notifications has increased steadily from 1974 onwards, but it was difficult to use surname-ascribed ethnicity variables to determine whether immigration has lead to the recent increase in tuberculosis notifications. Some of the nonCaucasian cases may be second and subsequent generation immigrants. However, the Jarman index measure of ethnicity records only first generation immigrants, and in the 1980 s the variation in tuberculosis rates throughout Liverpool could only be explained by a single measure of deprivation: unemployment. The fact that in the $1990 \mathrm{~s}$ the ethnic proportion of council ward populations had a significant independent influence on the distribution of tuberculosis (as well as two indices of deprivation: overcrowding and elderly living alone), suggests that immigration, although not necessarily the only factor causing the increase in notifications, was actually influencing the distribution of the disease within the city.

This phenomenon has been shown to occur throughout metropolitan districts of England and boroughs of London [5]. Thus, the distribution of tuberculosis in this country can more accurately be explained by both measures of ethnicity and deprivation than by either factor alone. This is in contrast to a previous study which concluded that deprivation alone was responsible for the national rise in tuberculosis [7].

The possibility that tuberculosis is being re-introduced into communities in developed countries as a result of migration from developing countries may become a matter of political debate. It is generally realized by the medical services that immigrants from developing countries have a high risk of tuberculosis, so the diagnosis is usually made early [13]. That tuberculosis is a continuing problem in the Caucasian population is not so well known ( $72 \%$ of cases in Liverpool are still in this population), with the result that diagnosis is delayed and infection and disease are passed onto contacts, usually within the family. Deoxyribonucleic acid fingerprinting has shown high levels of case clustering in Caucasian populations, but an absence of case clustering in immigrant populations, supporting the theory that immigrants acquire their infection abroad [13, 14] (P.C. Hopewell, San Francisco General Hospital, San Francisco, CA, USA, personal communication). Tuberculosis in Caucasian populations tends to occur in clusters as they infect each other, within the family or in the community [14, 15].

Tuberculosis is a disease that peaked in incidence in Europe approximately 200 yrs ago and was then spread to the rest of the world by trade and colonial expansion. The disease has therefore peaked more recently in developing countries and these countries now have a population with much higher rates than indigenous Europeans [16].

When the tuberculosis cases are divided into Caucasian and non-Caucasian categories, the incidence of tuberculosis shows a different pattern across age groups. There was a greater proportion of cases $(25 \%)$ in non-Caucasians in the younger age groups (20-29 yrs), while in the Caucasian group, the greater number of cases appear in the elderly, $40 \%$ are aged $\geq 60$ yrs. Young foreign-born persons, with latent infections, represent a growing proportion of tuberculosis cases in whom active disease will continue 
Table 1. - Multiple regression analysis using 1981 underprivileged variables of the Jarman index

\begin{tabular}{lcc}
\hline Variable & $\mathrm{r}^{2}$ & $\mathrm{p}$-value \\
\hline $\begin{array}{l}\text { Dependent variable } \\
\text { Tuberculosis rate 1981-1985 }\end{array}$ & \\
Independent variables & \\
$\quad$ Unemployment & 0.58 & \\
Excluded variables & $<0.001$ \\
Elderly living alone & & \\
Ethnicity & 0.17 \\
Moved house & 0.09 \\
No amenities & 0.18 \\
Single parent & 0.98 \\
Overcrowding & 0.94 \\
Aged over 65 & 0.17 \\
Aged under 5 & 0.18 \\
Unskilled & 0.86 \\
\hline
\end{tabular}

to develop unless major efforts are mounted to screen for infection and provide preventative therapy [17]. Revisits to the country of origin of parents are also a likely cause of higher rates [18].

As the transmission of the disease over the past decades has declined in developed counties, higher rates of tuberculosis have increasingly been associated with the elderly [19]. Reactivation in the elderly may occur as immunity declines with age, a trend that is likely to increase as life expectancy increases. This trend is consistent with the finding of the present study that elderly people living alone has become a significant variable influencing tuberculosis. This trend may become stronger as life expectancy continues to improve, particularly in developing countries. The implications for an increased burden of disease with ageing is therefore appreciable [20], so that the elderly will continue to be an important source of infection within the community.

In 1991-1995, overcrowding in Liverpool was also found to be significantly associated with tuberculosis. It is unclear why this should be a significant independent factor in 1991 and not 1981. By contrast, MANGTANI et al. [6] using 1981 census variables found that overcrowding affected tuberculosis rates in London. It remains probable that overcrowding results in the increased transmission within the community and therefore needs to be addressed by the appropriate social and local authorities, particularly in re-

Table 2. - Multiple regression analysis using 1991 underprivileged variables of the Jarman index

\begin{tabular}{lcc}
\hline Variable & $\mathrm{r}^{2}$ & $\mathrm{p}$-value \\
\hline Dependent variable & & \\
$\quad$ Tuberculosis rate 1991-1995 & & \\
Independent variables & & \\
$\quad$ Ethnicity & 0.22 & $<0.01$ \\
Overcrowding & 0.37 & $<0.001$ \\
$\quad$ Elderly living alone & 0.51 & $<0.001$ \\
Excluded variables & & \\
Moved house & & 0.88 \\
No amenities & & 0.91 \\
Single parent & & 0.71 \\
Aged over 65 & & 0.92 \\
Aged under 5 & & 0.19 \\
Unemployment & & 0.18 \\
Unskilled & & 0.83 \\
\hline
\end{tabular}

lation to the inspection and regulation of houses of multiple occupation.

The fact that unemployment was an independent factor in 1981 but not in 1991 may be related to the possibility that the real incidence of unemployment is not reflected in official figures. The strong relationship between tuberculosis and indices of deprivation remains consistent with the hypothesis that the rise in tuberculosis may be related to a rise in underlying social deprivation among a minority of the population $[4,5]$.

The possibility that the introduction of the Consultant in Communicable Disease Control in 1988 may have improved the completeness of notifications, resulting in an apparent increase, has been suggested and may in part explain the increase in notifications for nonpulmonary tuberculosis [1]. However, it is unlikely that this would have been a factor in the two-fold increases of cases in Liverpool between 1987 and 1993. Tuberculosis has been increasing in many developed countries within the last decade. The reason for this has been shown to be variable and therefore deserves further investigation. This will enable interventions and resources to be targeted to maintain control and allow work towards the elimination of tuberculosis.

\footnotetext{
Acknowledgement. The authors are grateful to S. Jamieson and C. Williams for assistance with the database of notifications. Special thanks to M. Bellis for statistical advice and comments on a previous version of the manuscript.
}

\section{References}

1. Hayward AC, Watson JM. Tuberculosis in England and Wales 1982-1993. Notifications exceed predictions. Commun Dis Rep 1995; 5: R29-R33.

2. Sudre P, Ten Dam HB, Kochi A. Tuberculosis: a global overview of the situation today. Bull WHO 1992; 70 : 149-159.

3. Doherty MJ, Spence DPS, Davies PDO. The increase in tuberculosis notifications in England and Wales since 1987. Tuberc Lung Dis 1995; 76: 196-200.

4. Spence DPS, Hotchkiss J, Williams CSD, Davies PDO. Tuberculosis and poverty. BMJ 1993; 307: 759-761.

5. Tocque K, Doherty MJ, Bellis MA, Spence DPS, Williams CSD, Davies PDO. Tuberculosis notifications in England: the relative effects of poverty and ethnicity. Int J Tuberc Lung Dis 1998; 2: 213-218.

6. Mangtani P, Jolley DJ, Watson JM, Rodrigues LC. Socioeconomic deprivation and notification rates for tuberculosis in London during 1982-1991. BMJ 1995; 310: 963-966.

7. Bhatti N, Law MR, Halliday R, Moore-Gillon J. Increasing incidence of tuberculosis in England and Wales: a study of the likely causes. BMJ 1995; 310: 967-969.

8. Rieder HL. Epidemiology of tuberculosis in Europe. Eur Respir J 1995; 8: Suppl 20, 620s-632s.

9. Stehr-Green JK. Tuberculosis in New Zealand, 1985-90. N Z Med J 1992; 105: 301-303.

10. Enarson DA, Dirks JM. The incidence of tuberculosis in a large urban area in Canada. Am J Epidemiol 1989; 129: $1268-1276$.

11. Office of National Statistics Directory of Ethnic Names. London, Social Statistics Unit, 1987. 
12. Stillitoe K. Ethnic origin: the search a question. Pop Trends 1978; 13: 25-30.

13. Yang ZH, De Haas PEW, Wachmann CH, Van Soolingen D, Van Embden JDA, Anderson AB. Molecular epidemiology of tuberculosis in Denmark. $J$ Clin Micro 1995; 33: 2077-2081.

14. Burman WJ, Reevs RR, Hawkes AP, et al. DNA fingerprinting with two probes decreases clustering of $M$. tuberculosis. Am J Crit Care Med 1997; 155: 1140-1146.

15. Syed Q, Bellis M, Beeching NJ, et al. Tuberculin testing in two Liverpool social clubs: the effects of a tuberculosis outbreak on background positivity. Thorax 1996; 51: 624-627.

16. Davies PDO. Tuberculosis and migration. J Roy Coll Phys Lon 1995; 29: 113-118.
17. McKenna MT, McCray E, Onorato I. The epidemiology of tuberculosis among foreign-born persons in the United States, 1986 to 1993. N Engl J Med 1995; 332: 10711076.

18. McCarthy OR. Asian immigrant tuberculosis - the effect of visiting Asia. Br J Dis Chest 1984; 78: 248-253.

19. Kumar D, Watson JM, Charlett A, Nicholas S, Darbyshire JH. On behalf of Public Health Laboratory service/ British Thoracic Society/Department of Health collaborative group. Tuberculosis in England and Wales in 1993: results of a national survey. Thorax 1997; 52: 1060-1067.

20. Davies PDO. Tuberculosis in the elderly, epidemiology and optimal management. Drugs Ageing 1996; 8: 436444. 